\title{
Analysis on Bouguer gravity anomaly characteristics and boundary identification in China and surrounding regions
}

\author{
Zhixin Xue ${ }^{1,2}$, Dongmei Guo ${ }^{1, *}$, Honglei $\mathrm{Li}^{3}$, and Panpan Zhang ${ }^{1,2}$ \\ ${ }^{1}$ State Key Laboratory of Geodesy and Earth's Dynamics, Innovation Academy for Precision Measurement Science and \\ Technology, Chinese Academy of Sciences, Wuhan, China \\ ${ }^{2}$ University of the Chinese Academy of Sciences, Beijing, China \\ ${ }^{3}$ Institute of Geophysics, China Earthquake Administration, Beijing, China
}

\section{Article history:}

Received 12 January 2021

Revised 17 June 2021

Accepted 22 June 2021

\section{Keywords:}

Bouguer gravity anomaly, Gravity interpretation, Tectonic stress field, Edge detection, Tectonic division

Citation:

Xue, Z., D. Guo, H. Li, and P. Zhang, 2021: Analysis on Bouguer gravity anomaly characteristics and boundary identification in China and surrounding regions. Terr. Atmos. Ocean. Sci., 32, 797-812, doi: 10.3319/TAO.2021.06.22.02

\begin{abstract}
China is located in the southeast of the Eurasian Plate and is subject to the effects of subducting, squeezing and collision by the Pacific Plate, Philippine Plate and Indian Ocean Plate. It has exceptional geotectonic structure. Based on the satellite gravity data with high precision, high resolution and ample geophysical information, combined with geological data, by using satellite gravity potential field and its full tensor gradient, this paper studies the distribution characteristics of gravity anomalies and the identification of tectonic boundaries in East Asia. Results suggest that the Bouguer gravity anomaly in eastern China reduces gradually from east to west, mostly in the direction of NNE; in the western, it reduces gradually in a wave mode from north to south, mainly in the directions of NW and NWW. In general, the stress field reduces gradually from west to east, and the tectonic of stress field in western China is complex. The change in eastern China is relatively simple. In addition to the above study results, we update the extension route of Red River fault zone and deduce the tectonic unit boundary between the North China and South China active tectonic block regions. This paper identifies in East Asia 6 primary active tectonic blocks, 22 secondary active tectonic blocks, 7 tertiary active tectonic blocks, and the 20 active tectonic block boundary zones. The results of this study can improve the understanding of gravity anomalies and boundary structures in China and surrounding regions, and provide certain geophysical supports for geological structure analysis and crustal dynamic process.
\end{abstract}

\section{INTRODUCTION}

China is located in the southeast of the Eurasian Plate and is subject to the effects of subducting, squeezing and collision by the Pacific Plate to the east, Philippine Plate to the southeast and Indian Ocean Plate to the southwest. With its exceptional geotectonic structure, this country has always drawn high attention from domestic and foreign scholars. After the plate tectonics theory was introduced to China in late 20th century, numerous renowned scholars have offered innovative insights regarding the geotectonic structure of China (Li 1973; Molnar and Tapponnier 1975; Teng et al. 1979; Deng et al. 2003b; Zhang et al. 2003, 2005). In the last century, many scholars have tried many methods from many

\footnotetext{
* Corresponding author

E-mail: guodongmei@whigg.ac.cn
}

aspects to add to and update the understanding of China's geological structure (Xiong et al. 2018), which has been crucial to the study on geotectonic zoning and evolution of China and prediction and prospecting of mineral resources.

Due to the importance of the geological environment in the study area, researchers have carried out a lot of geophysical exploration work in East Asia. The results of gravity anomalies in mainland China reflect certain structural feature information (Ma et al. 2006; Yang et al. 2016). However, it mainly reflects vertical geological information, and its resolution is limited compared to gravity gradient data. According to the theory of plate tectonics, seismic detection and aeromagnetic survey, there are many division schemes for Chinese geotectonic divisions, but some controversies are still existed in study area, such as the tectonic division 
in South China Sea is still unclear. There are still some questions about the boundary between the North China and South China (Li 1973; Deng et al. 2003b; Zhang et al. 2003; Xiong et al. 2018). And, large-scale ground observation data is difficult to obtain and have limited accuracy. At the same time, the research methods are expensive and difficult to popularize. The interaction of China's internal structure will have different responses to the tectonic stress field, which will lead to regional changes in the direction of the principal stress (Xie et al. 2004; Xu et al. 2008). While, this method also has limitations such as high construction costs, difficulty in data acquisition, and difficulty in implementation in special fields for instance oceans.

Boundary identification is an important part of gravity data interpretation. It can help scholars in the division of geological structures. Most of the existing traditional boundary identification methods are based on the horizontal and vertical derivatives of gravity anomalies. Such as the total horizontal derivative and amplitude of the analytic signal (Cordell 1979; Nabighian 1984; Cordell and Grauch 1985; Roest et al. 1992). These methods are accurate for the recognition of shallow anomaly boundaries. The tilt derivative (Miller and Singh 1994) can equalize anomalous information with different amplitude intensities. The total horizontal derivative of the tilt derivative can also be used for boundary identification (Verduzco et al. 2004). The Theta map can determine boundary position through the maximum value (Wijns et al. 2005). However, the traditional methods based on the horizontal and vertical derivatives of gravity anomalies are very sensitive to noise, and it is difficult to effectively balance the amplitudes of deep and shallow anomalies. When both positive and negative anomalies appear in the anomaly, false boundary results are likely to be produced.

In recent years, full tensor gravity gradient data which contains more information in different directions has been used to delineate the structural boundaries of geological bodies. Combining different tensor components can provide a more comprehensive understanding of the overall situation of the geological body. It has caused widespread concern (Bell et al. 1997; Zhdanov et al. 2004; Fedi et al. 2005; Mikhailov et al. 2007). Gao et al. (2011) used the gravity gradient tensor to study the faults and structures of the Hulin Basin in Heilongjiang Province. Dai et al. (2018) used the gravity gradient structure tensor eigenvalues to realize boundary identification. In order to fully use multiple component information of gravity gradient tensor data, $\mathrm{Yu}$ et al. (2019) proposed a new method of balanced edge detection for the gravity potential-field based on horizontal analytical signal. Each boundary identification method has its own characteristics and functions, and the problems that each method can solve are also different. Because of the complexity of geological phenomena, a single interpretation method has limitations. Based on previous research results, the paper comprehensively considers the full tensor gradi- ent of gravity and its various combinations to identify and analyze the structural boundaries of East Asia.

In view of the fact that there are still some controversies in the study of East Asian with tectonic division, the paper comprehensively uses various full tensor gravity gradient data combinations to study the structure and unit division of East Asia. First, free-air gravity anomaly and topography data are used to calculate the terrestrial-marine Bouguer gravity anomaly of East Asia and analyze the characteristics of geological bodies inside the crust that deviate from normal density; then we apply tectonic stress field with regional characteristics to identify the tectonic stress field and discuss the distribution characteristics of the tectonic movements of China and surrounding regions and their dynamics; finally, we use satellite gravity full-tensor gradient data and its combinations to identify the tectonic boundaries of faults, contact zones and other tectonic units and thereby divide the geological tectonic units of East Asia, identify the general outlines of the microplates and provide the tectonic basis for geological interpretation.

\section{THEORY}

\subsection{Tectonic Stress Field}

Tectonic stress field, that is, at a certain moment, there is a stress field inside the crust within a certain range that causes structural deformation and fracture. There is a close relationship between gravity field and the tectonic stress field. According to the Bouguer gravity anomaly, the Hilbert three-dimensional space potential field conversion formula can be used to derive the horizontal components $g_{x}$ and $g_{y}$ of gravity at a certain point $(x, y)$ (You 1994), as shown in the following formula

$$
\left\{\begin{array}{l}
g_{x}=-\frac{1}{2 \pi} \int_{-\infty}^{+\infty} \int_{-\infty}^{+\infty} \frac{(x-\xi) g_{z}}{\left[(x-\xi)^{2}+(y-\eta)^{2}+H^{2}\right]^{3 / 2}} d \xi d \eta \\
g_{y}=-\frac{1}{2 \pi} \int_{-\infty}^{+\infty} \int_{-\infty}^{+\infty} \frac{(y-\eta) g_{z}}{\left[(x-\xi)^{2}+(y-\eta)^{2}+H^{2}\right]^{3 / 2}} d \xi d \eta
\end{array}\right.
$$

Where $(\xi, \eta)$ is the flow coordinates throughout the whole measurement area, $g_{z}$ is the corresponding Bouguer gravity anomaly value; $H$ is the spatial continuation height; the integration area in the above formula can be finite and grid discretized.

The maximum principal compressive stress direction of the stress field can be determined by the horizontal direction of gravity, as shown in the following formula

$\beta=\arctan \frac{g_{y}}{g_{x}}$

The formula for calculating the tectonic stress field from 
gravity anomaly is shown below (Guo et al. 2017)

$\Delta \sigma_{x x}=\frac{g \rho_{i} g_{h}}{4 \pi f \rho_{m}}$

where $\rho_{i}$ is the mean crustal density, $\rho_{m}$ is the density of the mantle, which are respectively taken as 2670 and $3300 \mathrm{~kg} \mathrm{~m}^{-3} ; g$ is the average acceleration of gravity, $f$ is the gravitational constant, and $g_{h}$ is the horizontal component of gravity, namely $g_{h}=\left(g_{x}{ }^{2}+g_{y}^{2}\right)^{1 / 2}$.

\subsection{Boundary Identification Methods}

The two sides of linear structural belts, such as plate suture zone, various geological body boundaries, and faulted structural belts, often have a certain density difference, which causes large changes in gravity anomaly. According to the feature, gravity data can be used to study horizontal linear structures. Traditional linear structure research mainly uses the three directional $(\mathrm{x}, \mathrm{y}, \mathrm{z})$ derivatives of gravity for identification. However, this unidirectional angular boundary recognition method has a large error in the recognition of the boundary of a deeper geological body, and its resolution ability is insufficient when the geological bodies are very close. In order to detect the target more accurately, the method of full tensor gradient can be used. The full tensor gradient data is the derivative of the gravity vector $g=$ $\left(g_{x}, g_{y}, g_{z}\right)$ in three orthogonal directions $(x, y, z)$.

Through Fourier transform, the full tensor gradient of gravity can be calculated from the vertical gravity anomaly (Mickus and Hinojosa 2001).

$\Gamma=F^{-1}\left\{[K(k)] \bar{V}_{z}(k)\right\}$

in the above formula, $F^{-1}$ is the two-dimensional inverse Fourier transform, $\bar{V}_{z}(k)$ is the two-dimensional Fourier transform of vertical gravity anomaly; $K$ is the wave number vector, $|k|=\left(k_{x}^{2}+k_{y}^{2}\right)^{1 / 2}$, and $|k| \neq 0, k_{x}$ and $k_{y}$ are the wave numbers in the $x$ and $y$ directions respectively.

The expression of the gravity gradient tensor $\Gamma$ is as follows

$\Gamma_{p, q}=\left[\begin{array}{lll}V_{x x} & V_{x y} & V_{x z} \\ V_{y x} & V_{y y} & V_{y z} \\ V_{z x} & V_{z y} & V_{z z}\end{array}\right]$

where $p=x, y, z, q=x, y, z$.

It can be seen from the above formula that the nine gravity gradient tensors are symmetric: $V_{p q}=V_{q p}$, and its components $V_{x x}, V_{y y}$, and $V_{z z}$ satisfy the Laplace equation, namely $V_{x x}{ }^{2}+V_{y y}{ }^{2}+V_{z z}{ }^{2}=0$, so five components are independent of each other.
On the basis of the above calculations, this paper uses boundary detectors composed of gravity full- tensor gradient and its different combinations for boundary identification. The detailed combinations are shown below.

The THD (Cordell 1979; Cordell and Grauch 1985) can be described by

$\mathrm{THD}=\sqrt{V_{x z}^{2}+V_{y z}^{2}}$

THD is the abbreviation of "total horizontal derivative", and its maximum value can be used to determine the boundary position of the abnormal body.

The ASM (Nabighian 1984; Roest et al. 1992) can be described by

$\mathrm{ASM}=\sqrt{V_{x z}^{2}+V_{y z}^{2}+V_{z z}^{2}}$

ASM is the abbreviation of "amplitude of the analytic signal", and its maximum value can be used to determine the boundary position of the abnormal body.

The TDR (Miller and Singh 1994) can be described by

$\mathrm{TDR}=\arctan \left(\frac{V_{z z}}{\sqrt{V_{x z}^{2}+V_{y z}^{2}}}\right)$

TDR is the abbreviation of "tilt derivative", which divides the fracture location according to the zero-value line and the nearby isoline.

The THDR (Verduzco et al. 2004) can be described by

$\mathrm{THDR}=\sqrt{\left(\frac{d \mathrm{TDR}}{d x}\right)^{2}+\left(\frac{d \mathrm{TDR}}{d y}\right)^{2}}$

THDR is the abbreviation of "total horizontal derivative of the tilt derivative", and its maximum value can be used to determine the boundary position of the abnormal body.

The $\theta$ (Wijns et al.2005) can be described by

$\theta=\arccos \left(\frac{\sqrt{V_{x z}^{2}+V_{y z}^{2}}}{\sqrt{V_{x z}^{2}+V_{y z}^{2}+V_{z z}^{2}}}\right)$

$\theta$ is the abbreviation of "Theta map", and its maximum value can be used to determine the boundary position of the abnormal body.

\section{DATA}

The study scope of this paper is $65-145^{\circ} \mathrm{E}, 0-60^{\circ} \mathrm{N}$; the gravity and topography data are sourced from the V28.1 Gravity Model and the V18.1 Topography Model published 
by Scripps Institution of Oceanography (SIO), where the spatial resolution of the data is $1^{\prime} \times 1$ '. The SIO V28.1 Gravity Model consists of the land gravity anomaly data of EGM2008 (Earth Gravitational Model 2008) and ocean gravity anomaly data from satellite altimetry.

\subsection{Topography Data}

This paper uses the V18.1 Topography Model with spatial resolution 1' $\times 1^{\prime}$ '; the data cover $0-360^{\circ} \mathrm{E}$ longitude and $-80.738-80.738^{\circ} \mathrm{N}$ latitude; the vertical datum is the sea level; Mercator projection is used. Figure 1 shows the topographic map of China and surrounding regions.

As shown in Fig. 1, China has numerous mountains and complex and diverse terrains; it has three steps of topography, with the west parts higher than the east parts; the mountains constitute a network that exists throughout China mainland. The first step has average altitude of above $4500 \mathrm{~m}$ and contains the Qinghai-Tibet Plateau of Southwest China and the Qaidam Basin. To the east and north of the second step are Kunlun Mountains-Altyn Tagh Mountains-Qilian Mountains-Hengduan Mountains, which is the boundary between the first and second steps; to the east are the Great Higgnan Mountains-Taihang Mountains-Wushan Mountain-Xuefeng Mountain, which is the boundary between the second step and third step. The second step has average altitude of 1000 - $2000 \mathrm{~m}$ and contains large basins and plateaus, e.g., Tarim Basin and Sichuan Basin. The third step, located to the east of the second step, has altitude of mostly less than $500 \mathrm{~m}$ and flat terrain, e.g., North China Plain. To the east of the third step is the continental shelf, which is the extension of China Mainland into the ocean. Overall, Fig. 1 accurately indicates China's topographic characteristics, where the west is higher than the east and south higher than the north. The maximum topography elevation exists in the Hengduan Mountains and Tianshan Mountains, from which the elevation reduces in both directions; the minimum elevation exists in the flat areas in East China.

\subsection{Free-Air Gravity Anomaly}

Free-air gravity anomaly changes drastically in the areas with great terrain undulation. As shown in Fig. 2, the areas with great terrain undulation have clearly identifiable boundaries between mountains and basins, which is highly indicative of the structure of the tectonic blocks in the study area. The east and west parts of China, roughly taking $105^{\circ} \mathrm{E}$ as the boundary, have significant difference in freeair gravity anomaly. East China has generally flat terrain and therefore mild anomaly variation; West China has great terrain undulation and therefore drastic anomaly variation.

East China has two noticeable NNE (north-northeast) positive linear anomaly belts. One starts from Changbai Mountain in Northeast China, extends along Shandong Pen- insula and towards the coastal areas of Zhejiang and Fujian; the other one starts from Great Higgnan Mountains, extends along Taihang Mountains, passes the Yinshan Mountains and Qinling Mountains which are nearly in EW (east-west) direction and extends towards to West Hubei and West Hunan. Due to the Ordos Basin and Sichuan Basin, the NNE linear anomaly is not continuous and has distortion along the way. The plain area between the two anomaly belts has mild anomaly amplitude variation, occasionally negative but mostly positive.

West China has drastic anomaly variation, with positive and negative anomalies alternating with each other. The drastic variation of anomaly amplitude perfectly corresponds to the topographic characteristics shown in Fig. 1. Tarim Basin, Qaidam Basin, and Junggar Basin mostly have negative anomalies. The Qinghai-Tibet Plateau has clearly identifiable boundary, where the surrounding mountains all have positive anomalies and drastic variation and the $\mathrm{Hi}$ malayas have immense anomaly variation amplitude. The west of Qinghai-Tibet Plateau also has noticeably drastic positive anomaly variation, but positive anomalies and negative anomalies alternate with each other in the interior of Qinghai-Tibet Plateau, with mild anomaly variation.

\section{RESULTS AND ANALYSIS}

\subsection{Bouguer Gravity Anomaly}

By using the free-air gravity anomaly data and topography data obtained and making Bouguer correction and terrain correction (Fullea et al. 2008), the 1' $\times 1$ ' complete Bouguer gravity anomaly is obtained (Fig. 3). As indicated in Fig. 3, among the Bouguer gravity anomalies, the east one is greater than the west one and north one greater than south one. The Bouguer gravity anomaly, approx. $-740 \mathrm{mGal}$, exists in Qinghai-Tibet Plateau; the value increases gradually eastward and northward; the eastern coastal region of China has low Bouguer gravity anomaly. Roughly taking $105^{\circ} \mathrm{E}$ as the boundary, the east and west parts of China have significant difference in Bouguer gravity anomaly. The eastern region has mild Bouguer gravity anomaly variation, while the western region has drastic Bouguer gravity anomaly variation.

In East China, Bouguer gravity anomaly reduces gradually from east to west, largely in the NNE direction, e.g., the two Bouguer gravity anomaly gradient belts that run from north to south of China. One is the gravity gradient belt through Great Higgnan Mountains-Taihang MountainsWuling Mountain. The other one is the gravity anomaly gradient belt through Helan Mountain-Liupan Mountain-Longmenshan Mountains-Wumeng Mountain. In the eastern coastal areas in Zhejiang and Fujian, there is also a smaller gravity anomaly gradient belt.

In West China, the minimum gravity anomaly is approx. $-80 \mathrm{mGal}$ in Junggar region in the north and approx. 


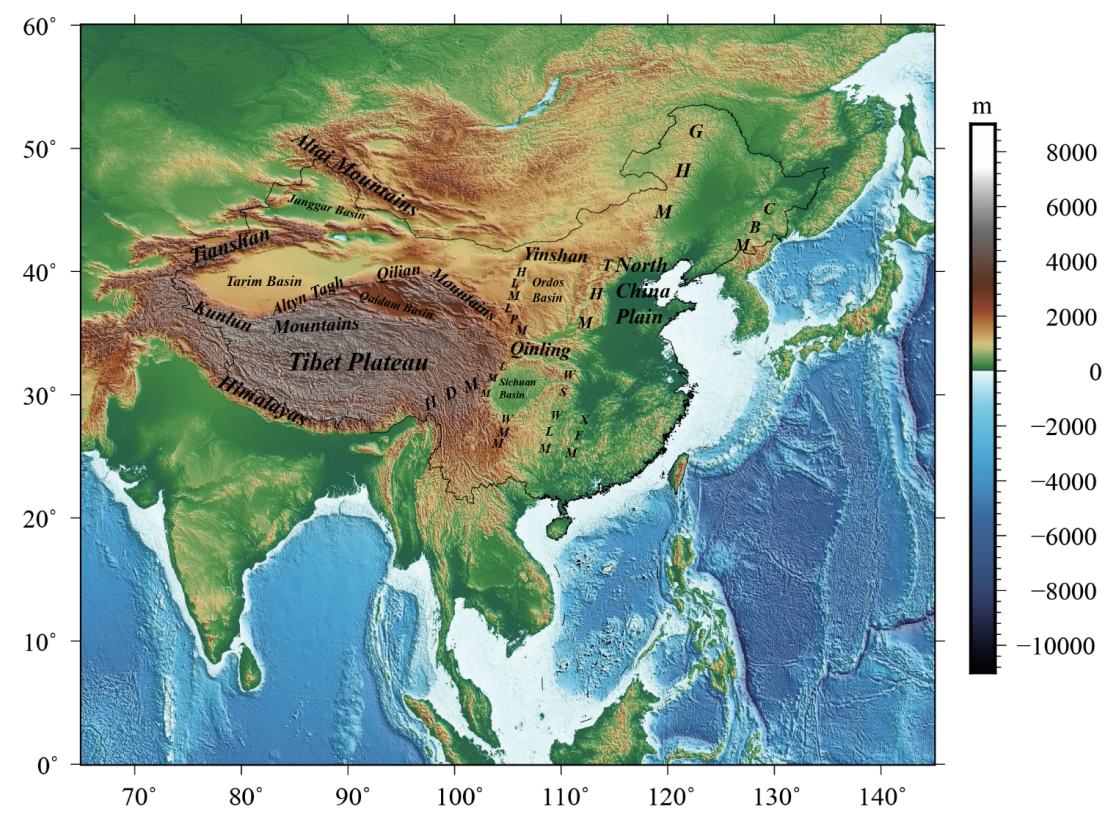

Fig. 1. The topographic map in China and surrounding regions.

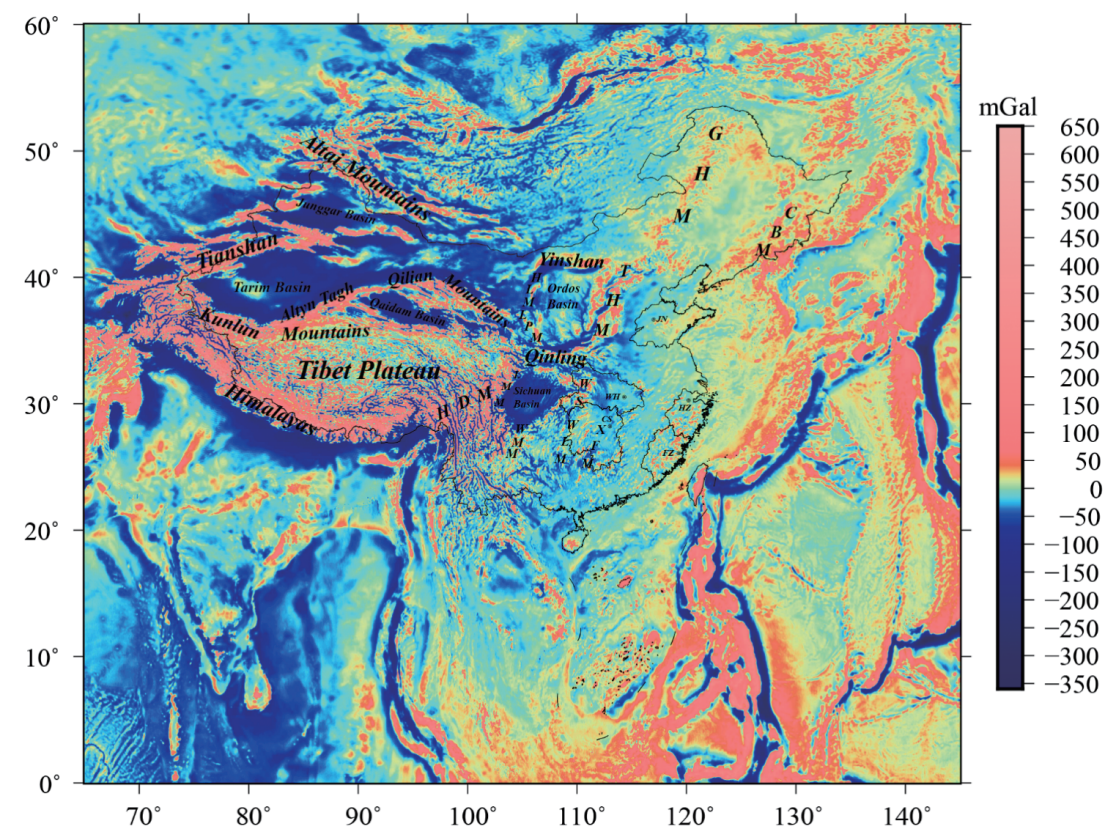

Fig. 2. The Free Air gravity anomaly in China and surrounding regions. 


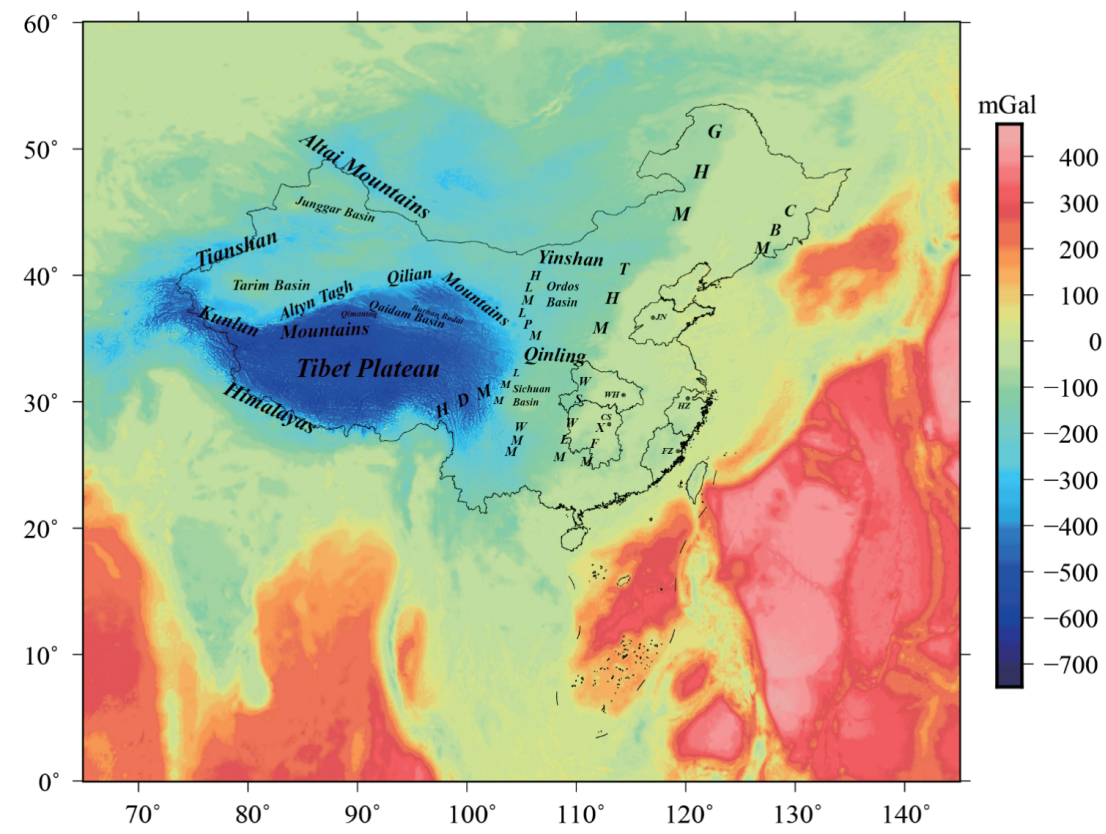

Fig. 3. The Bouguer gravity anomaly in China and surrounding regions.

-740 $\mathrm{mGal}$ in Qinghai-Tibet Plateau; Bouguer gravity anomaly generally reduces in a wave mode from north to south; largely in the NW (north-west) and NWW (westnorthwest) directions, there are four obvious gravity gradient belts. One is the gravity gradient belt through the Altai Mountains and Tianshan Mountains in the north; one is the gravity gradient belt through the Altyn Tagh Mountains and Qilian Mountains, which bends from west to south; one is the gravity gradient belt through the Qimantag Mountains and Burhan Budai Mountains in the south of Qaidam Basin, which bends from west to southeast; one is the gravity gradient belt through the Himalaya Mountains and Hengduan Mountains, which extends in arc-like form. Gravity anomaly has drastic variation along the margin of plateau and mild variation within plateau.

\subsection{Tectonic Stress Field Analysis}

The driving force for geologic structure is lateral pressure, which causes stress field changes inside the crust. On this basis, tectonic stress can be used to analyze the dynamic characteristics of crustal movement. By using the three-dimensional space potential field conversion formula of Hilbert (You 1994), the tectonic stress field of China and surrounding regions is calculated (Guo et al. 2017), as shown in Fig. 4.

China and surrounding regions are located in the southeast of Eurasian Plate and are subject to the effects of subducting, squeezing and collision by the Pacific Plate to the southeast, Philippine Plate to the southeast and Indian Ocean Plate to the southwest. The strong effects of the surround- ing plates have given rise to the unique lithospheric stress field and tectonic movement (Tapponnier et al. 1982; Xu et al. 1988; Molnar 1990; Avouac and Tapponnier 1993). The tectonic stress in China and surrounding regions is noticeably zoned and non-uniform and generally reduces gradually from west to east. The stress is greater in West China than in East China.

In East China, China mainland and surrounding areas are subject to the squeezing action in NEE (east-northeast) - SWW (west-southwest) direction, which is basically the direction in which the Pacific Plate and Philippine Plate jointly impose subduction to the Eurasian Continent. In the GPS horizontal velocity field in Fig. 5 (Zhao et al. 2015), the Pacific Plate and Philippine Plate have great velocity in the NW direction. The maximum principal compressive stress resulting from the subduction jointly imposed by the surrounding plates is in NE (north-east) - NEE direction in Northwest China and North China and in NW-SE direction in South China. As shown in Fig. 5, the North China and South China tectonic blocks generally move to the southeast and faster the further south; the areas near the northeast tectonic block are the slowest.

In West China, China mainland and surrounding regions are subject to squeezing in largely the SN (northsouth) - NNE direction, which is basically the direction in which the Indian Ocean Plate impose the northward collision to the Eurasian Continent. As shown in Fig. 5, the Indian Plate moves fast in the NE direction. Xinjiang is subject to the northward force imposed by Qinghai-Tibet tectonic block, so the maximum principal compressive stress is mostly in the SN direction. Qinghai-Tibet Plateau 


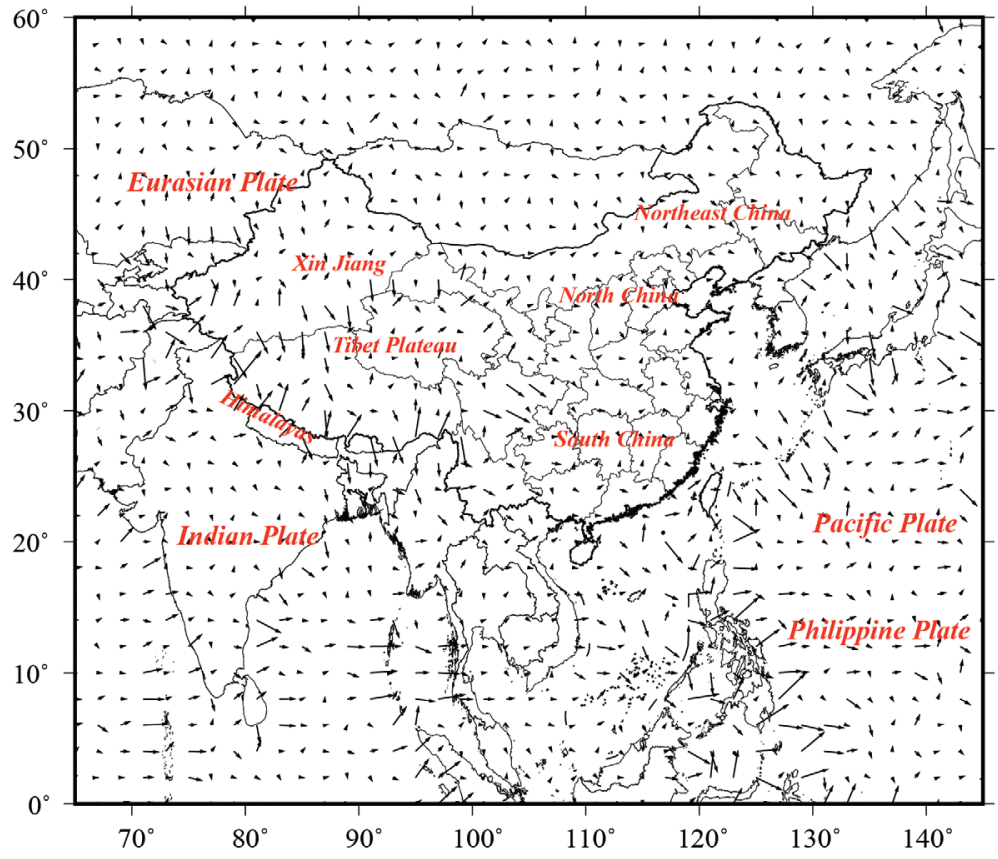

Fig. 4. Tectonic stress field vector in China and surrounding regions. Black solid lines are the state boundaries, where the thick black solid line represents the national boundary of China, the light black solid line represents the boundary of China's provinces, and black arrows denote vectors of the maximum principal compressive stress.

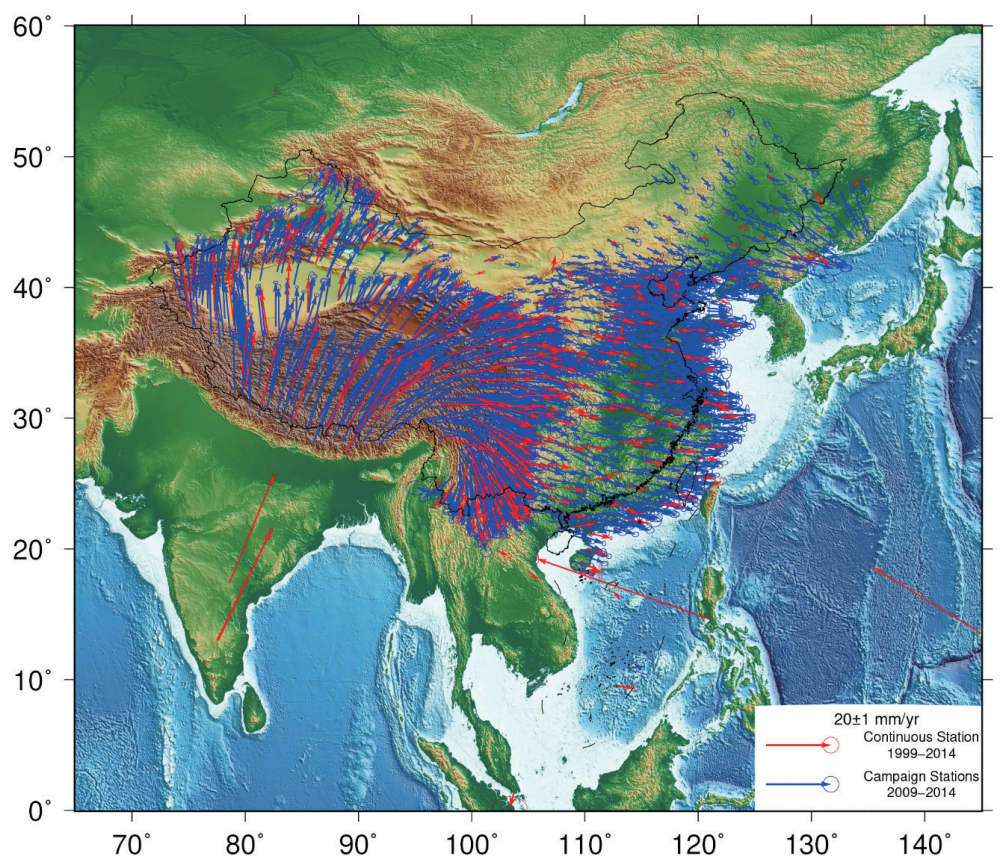

Fig. 5. Horizontal GPS velocities in China and surrounding regions (Zhao et al. 2015). 
is subject to the collision imposed by the Indian Plate, so the maximum principal compressive stress direction is very complex, where it is in NNE direction in the main part and in NNE-NE, NEE, nearly EW, SE (south-east), and SSE (south-southeast) directions along the northern margin extending from southeast to southeast borders. As clearly indicated in Fig. 5, the areas around Qinghai-Tibet Plateau move fast; the northward movement velocity of the tectonic blocks reduces gradually from west to east and they generally revolve clockwise around the Himalaya Mountains; the movement is in NE direction to the east of Qinghai-Tibet Plateau.

The stress between Indian Plate and Eurasian Plate is mostly in NE direction and is largely perpendicular to the plate boundary, which is confirmed by Fig. 5. The great stress values mostly exist on the tectonic boundary between the plates. The maximum value calculated in this paper is $>40 \mathrm{Mpa}$, which exists on the tectonic boundary. However, they mostly do not coincide with the plate tectonic boundary and their maximum value coincides with the part of the crust with the maximum thickness (Tenzer et al. 2017). Overall, the tectonic stress in China mainland and surrounding regions is very complex, GNSS horizontal velocity field and stress field generally have the same trend and the tectonic stress generally indicates the relevant geological activities.

\subsection{Boundary Identification}

On the basis of the Bouguer gravity anomaly data, we calculate the satellite gravity full-tensor gradient data and use the boundary identification methods with various combinations to identify the tectonic boundaries of China and surrounding regions (see Figs. 6 and 7). As indicated in Figs. 6 and 7, in the boundary identification methods, the various components of gravity gradient tensor have different anomaly characteristics, which indicates the boundaries and fracture structures of the geological bodies in the study area: $V_{x x}$ and $V_{x z}$ represent the anomalous bodies position in the EW direction, $V_{y y}$ and $V_{y z}$ represent the anomaly position in the SN direction, $V_{x y}$ represents the anomaly position of the NE and NW directions; $V_{z z}$, similar to gravity anomaly effect, represents the change rate of gravity anomaly along the vertical direction and reveals more tectonic details. Total horizontal derivative, analytic signal and total horizontal derivative of tilt derivative are obviously advantageous in identifying wide and large fault zones and microplate outlines; tilt derivative and Theta map are developed from total horizontal derivative and analytic signal and are both angular boundary identification methods, which increase image interpretation resolution and are highly effective in identifying small fractures. Overall, every boundary identification method is limited to various extents in the study area, therefore boundary identification and analysis comprehensively take into account gravity full-tensor gradient and its various combinations, to identify and analyze the tectonic boundaries of East Asia.

Geological data, gravity anomaly, satellite gravity fulltensor gradient and other boundary identification methods are used for boundary identification in East Asia, as shown in Fig. 8. As indicated in Fig. 8, the main fractures identified in this paper are largely consistent with the ones previously identified by other people (Zhang et al. 2013). As seen in Fig. 8, due to the collision to East Asia caused by the Indian Plate to the southwest, the Himalaya active tectonic belt PB1 becomes the boundary active tectonic belt between Indian Plate and East Asia; the Philippine Plate constantly squeezes the Eurasian Plate in the NW direction and the Taiwan active tectonic belt PB2 becomes the boundary active tectonic belt between these two plates; Northeast China is located in the westmost part of the West Pacific subduction zone (Zhao et al. 2012). According to its gravity anomaly and Figs. 6 and 7, there is an obvious boundary active tectonic belt PB3 between Northeast China, West Pacific and North America Plate. The fault zones in Fig. 8 constitute the boundaries of some of the secondary active tectonic blocks.

It is worth noting that Zhang et al. (2003) deduced that the hidden fault in front of Dabie Mountains was the south boundary of North China Plain tectonic block. This paper believes that the Xinyang-Jinzhai fault zone and the east part of Changhua-Putuo fault zone may constitute the tectonic unit boundary between North China and South China active tectonic blocks. As seen in Fig. 2, positive and negative values alternate with each other to the north and south of this fault zone, but the south segment has great difference between positive and negative values while the north segment has mild variation; in Fig. 3, the south segment has noticeable difference while the north segment has no noticeable variation; as seen in Fig. 6, the two ends have significant variation in gradient, with the aforesaid fault zone as the boundary; the gradient directions on both sides also have difference; in Fig. 7, the two ends of the fault zone have obviously different colors, which is particularly clear in Figs. 7a - c. Therefore, this paper deduces that XinyangJinzhai fault zone and the east part of Changhua-Putuo fault zone constitute the tectonic unit boundary between the North China and South China active tectonic block regions. As clearly indicated in Fig. 7d, the Red River fault zone starts from the northwest corner of the South China Sea, extends along a SE anomaly belt, reaches near the Hainan Island, then extends nearly southward and finally connects the Yuedong-Wanan fault zone; in Figs. 7c and e, this anomaly belt has obviously different colors than the areas to its sides and there is a noticeable boundary. In Figs. 2 and 3, the gravity anomaly value of this anomaly belt is greater than that of the areas to its sides and has great difference from the nearby amplitude; in Fig. 6, both sides of this anomaly belt have significant variation, where the 

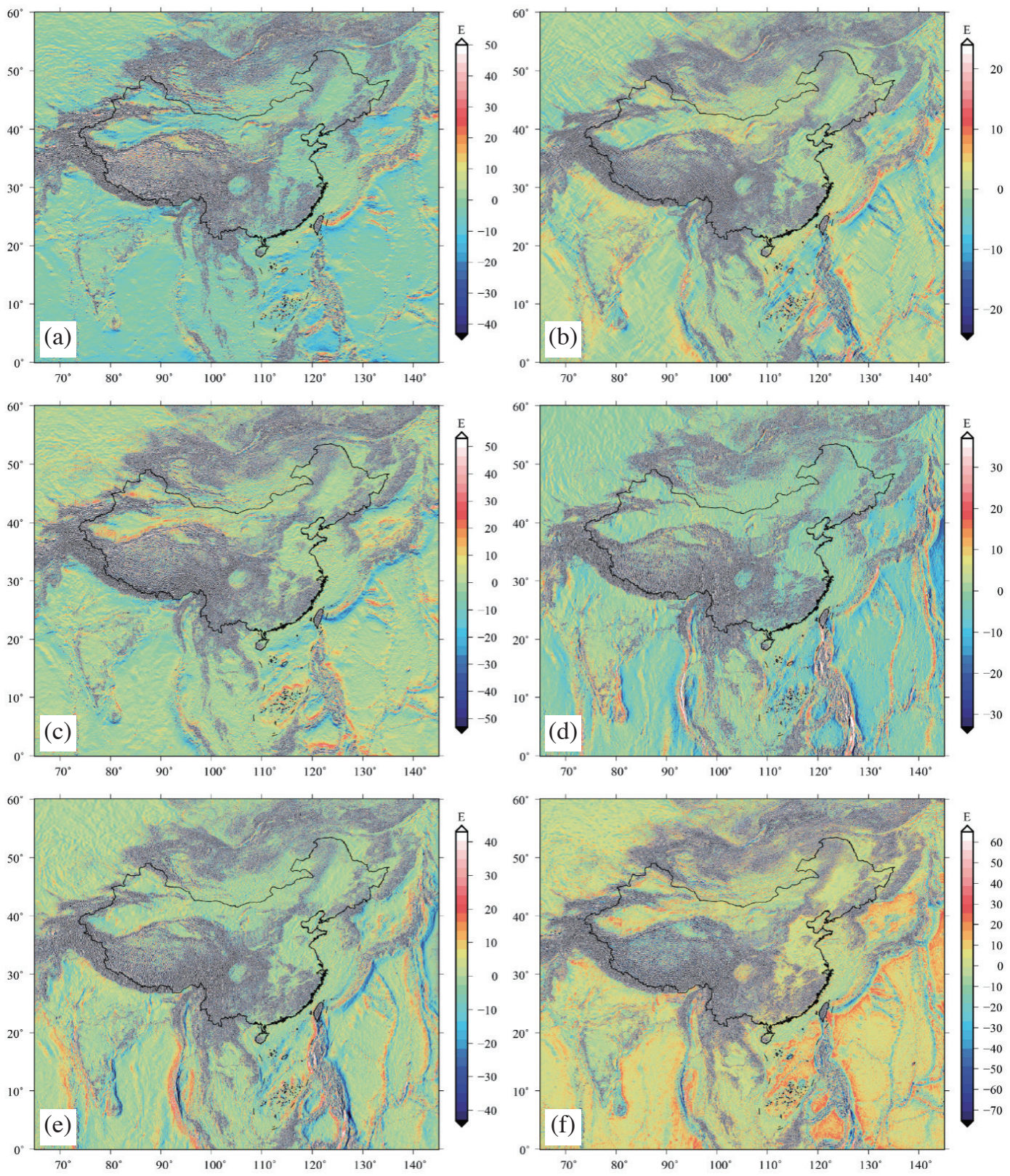

Fig. 6. Gravity anomaly gradient tensor- $V_{x x}, V_{x y}, V_{x z}, V_{y y}, V_{y z}, V_{z z}[(\mathrm{a})$ - (f)]. 

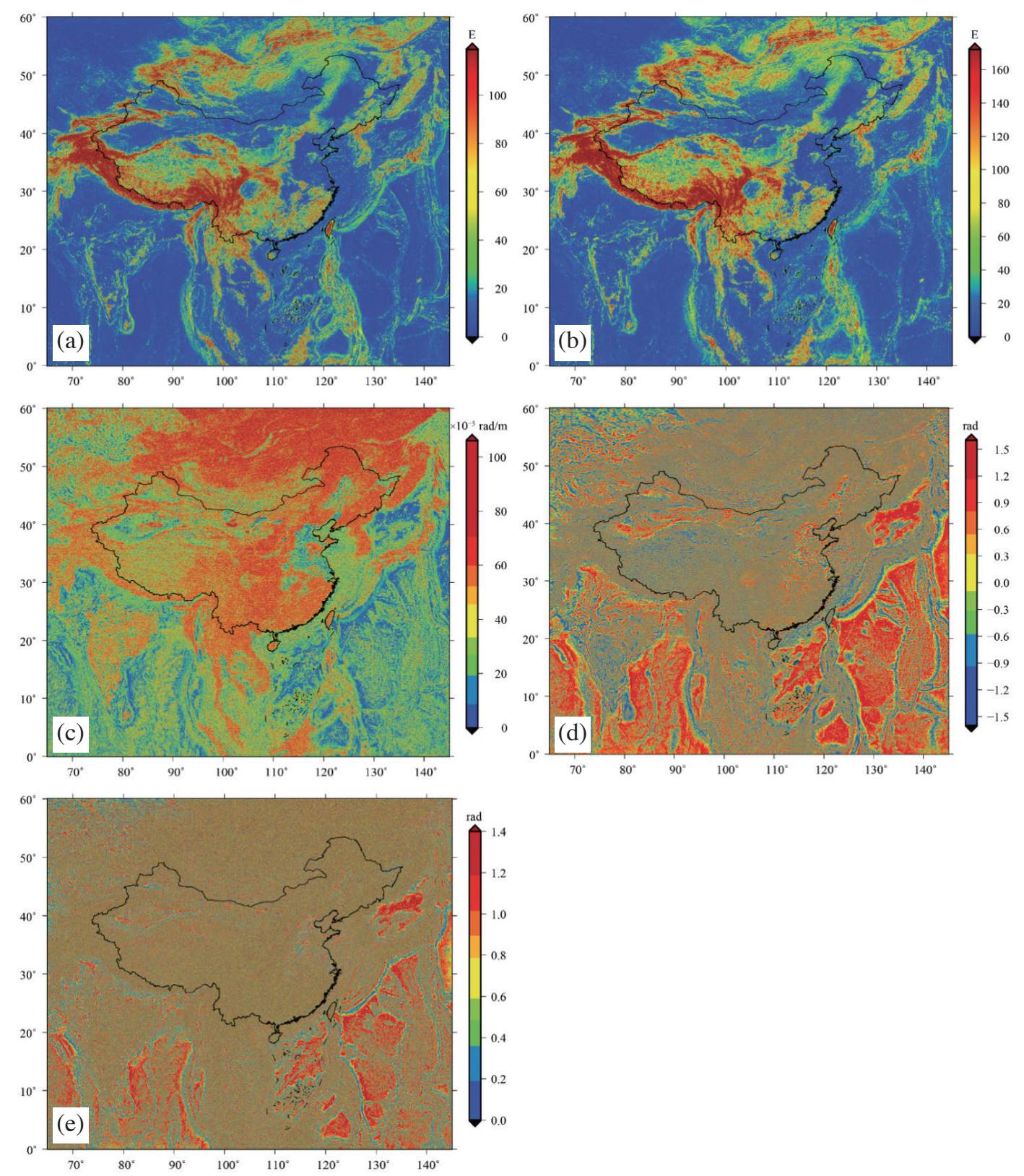

Fig. 7. Edge Detection data in China and surrounding regions (a) THD; (b) ASM; (c) THDR; (d) TDR; (e) $\theta$. 


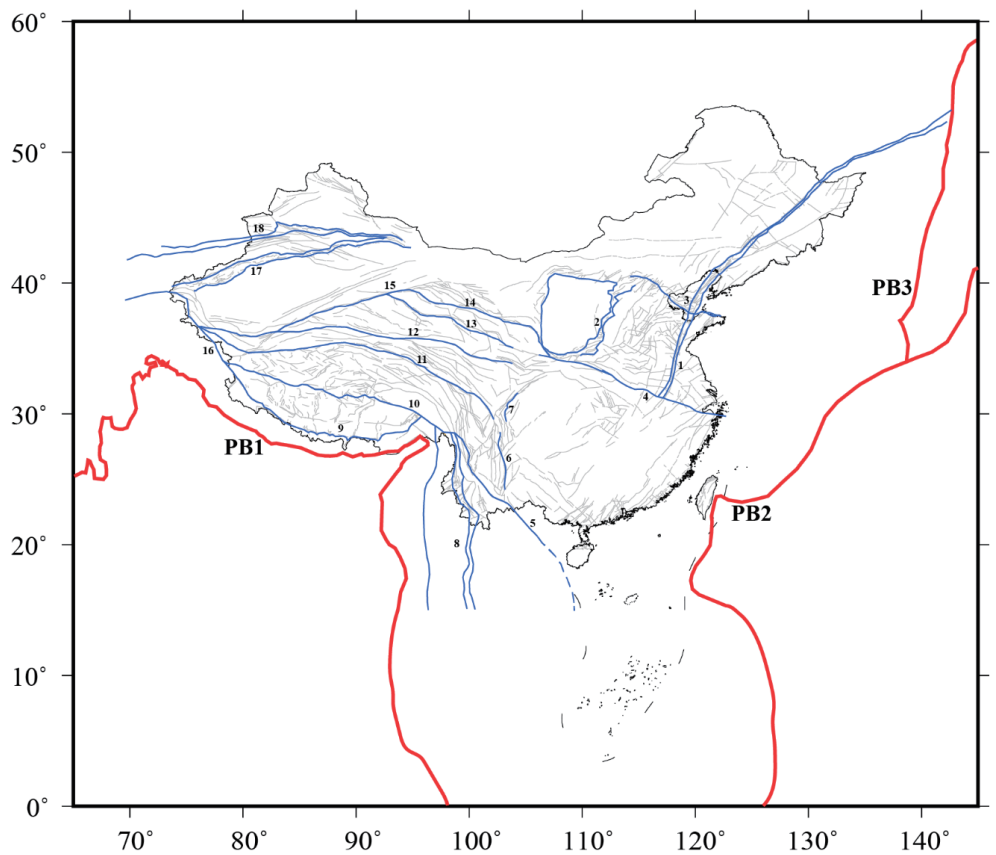

Fig. 8. The main edge results in China and surrounding regions. Line 1 is Tanlu fault zone; Line 2 is Shanxi fault zone; Line 3 is Zhangjiakou-Bohai fault zone; Line 4 is Xinyang-Jinzhai fault and the eastern part of Chang hua-Putuo fault; Line 5 is Red River fault; Line 6 is Xiaojiang fault zone; Line 7 is Longmenshan fault zone; Line 8 is Nujiang-Lancangjiang fault zone; Line 9 is Main Himalayan Thrust; Line 10 is Jiali fault zone; Line 11 is Xianshuihe fault zone; Line 12 is Kunlun fault zone; Line 13 is the West Qinling fault zone; Line 14 is Haiyuan fault zone; Line 15 is Altyn Tagh fault zone; Line 16 is Karakoram zone; Line 17 is Southern Tianshan fault zone; Line 18 is Northern Tianshan fault zone; PB1, PB2, PB3 represents active boundary zone between plates; The blue dotted line indicates the inferred extension of the Red River fault. And the gray solid line indicates other faults (Deng et al. 2003a).

values are greater than or less than this fault zone, with noticeable difference in color. This fact is highly similar to the study result of Dai et al. (2018), therefore this paper believes that the aforesaid anomaly belt is an extension of the Red River fault zone. This also reflects the effectiveness of the method in the paper.

\subsection{Tectonic Zoning}

In addition to the above study results, we completed tectonic zoning of China and surrounding regions by using the boundary identification methods based on the satellite gravity full-tensor gradient data and its combinations and taking into account the zoning principle for the active tectonic blocks of China and surrounding regions proposed by Zhang et al. (2003), the zoning principle for active fault blocks of China mainland proposed by Deng et al. (2003a) and the boundary distribution principle for the active tectonic blocks of China mainland proposed by Zhang et al. (2005). The following section will describe in detail the aforementioned tectonic zoning results. Compared with previous research results, the paper adopts high precision, high resolution satellite gravity data, which reflects more detailed geophysical information, and the results are more realistic and reliable.

\subsubsection{Northeast Asia Active Tectonic Block Region}

Northeast China is located the most active subduction zone in the world, i.e., the westmost part of the West Pacific subduction zone, where it is tectonically stable (Zhao et al. 2012). The prior section identified boundary active tectonic belt P3 between the plates. Figure 9 shows this region consists of 3 tectonic blocks, i.e., Yanshan, Xing'an-Dongmeng, and Dongbei. However, unlike the boundary deduced by Zhang et al. (2003), for the tectonic boundaries identified in Figs. 2, 3, 6, and 7 in this paper, the boundary of the primary active tectonic block regions is adjusted as shown in Fig. 9. The deduced boundary zone has clearly different color and difference value than the surrounding areas and can be clearly distinguished.

\subsubsection{North China Active Tectonic Block Region}

North China active tectonic block region is located to the south of Northeast Asia active tectonic block region. Figure 9 shows the North China active tectonic block region consists of 3 tectonic blocks, i.e., Ordos, North China Plain and Ludong-Huanghai. Figures 2, 3, 6, and 7 can all identify the Ordos tectonic block as a tectonic unit. Ordos tectonic block is subject to strong effect of squeezing by the 


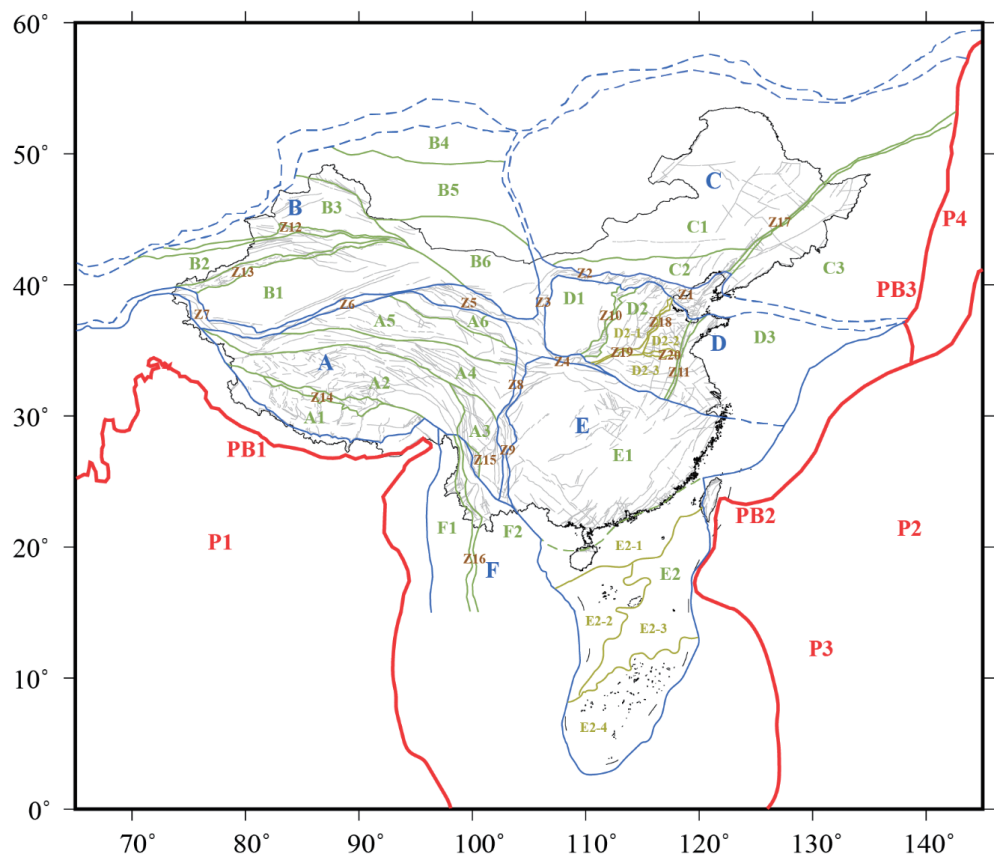

Fig. 9. Tectonic division in China and surrounding regions. A is Qinghai-Tibet active tectonic block regions, A1 is Lhasa block, A2 is Qiangtang block, A3 is Yunnan-Sichuan block, A4 is Bayan Har block, A5 is Qaidam block, A6 is Qilian block; B is Western Regions active tectonic block regions, B1 is Tarim block, B2 is Tianshan block, B3 is Junggar block, B4 is Sayan block, B5 is Altai block, B6 is Alxa block; C is Northeast Asia active tectonic block regions, C1 is Xing'an-Dongmeng block, C2 is Yanshanian block, C3 is Northeast block; D is North China active tectonic block regions, D1 is Ordos block, D2 is North China Plain block, D3 is Ludong-Huanghai block, D2-1 is Taihang Mountain block, D2-2 is Ji-Lu block, D2-3 is Yu-Huai block; E is South China active tectonic block regions, E1 is South China block, E2 is South China Sea block, E2-1 is Qiongtai tectonic block, E2-2 is Zhongxisha tectonic block, E2-3 is Central basin tectonic block, E2-4 is Nansha tectonic block; F is Yunnan-Myanmar active tectonic block regions, F1 is Western Yunnan block, F2 is South Yunnan block. P1 is Indian Plate, P2 is Pacific plate, P3 is Philippine Plate, P4 is North America plate. The red solid lines represent the plate active boundary, the blue solid lines represent the first-order active tectonic block boundary, the blue dotted lines indicate the inferred active tectonic block boundary, the green solid lines indicate the second-order active tectonic block boundary, and the yellow solid lines indicate the third-order active block boundary. And the gray solid line indicates other faults (Deng et al. 2003a). Z1 - Z20 represents the active tectonic zone between active blocks.

extension of the North China Basin and the northeast margin of Qinghai-Tibet Plateau and is divided by the Shanxi graben basin. This tectonic block is surrounded by very strong tectonic activities; tectonic deformation is dominated by strike-slip movement; it has weak interior tectonic activities; the boundary between the plate and the surrounding geological units is a fault zone (Wang et al. 2001). Different from the results of previous studies, the paper re-divides the boundary of the North China Plain based on high-precision, high-resolution satellite gravity data and a comprehensive combination of multiple full-tensor gravity gradient data. The North China Plain tectonic block has Zhangjiakou-Bohai fault zone as its north boundary, Tan-Lu fault zone as its east boundary, Shanxi graben basin as its west boundary and Xinyang-Jinzhai fault zone and the east part of Changhua-Putuo fault zone as its south boundary, which is also the tectonic unit boundary between the North China and South China active tectonic block regions, as described in detail in the preceding section. Taking into account the zoning principle for North China active tectonic block proposed by Han et al. (2003) and the internal outlines of North China Plain tectonic block as identified in Figs. 2, 6, and 7, the
North China Plain is divided into T'ai-hang tectonic, Jilu and Yuhuai tectonic blocks. And the naming proposed by Han et al. (2003) is still used, the boundary line is basically the same. This further proves the feasibility of this method.

\subsubsection{South China Active Tectonic Block Region}

South China active tectonic block region is located in Southeast China, in a stable plate, where it is relatively stable geologically. The boundary between this region and North China active tectonic block region is briefly described above. Figure 9 shows this tectonic block region consists of South China and South China Sea blocks. Unlike the zoning proposed by Zhang et al. (2003), this paper updates zoning of South China Sea block according to Figs. 2, 3, 6, and 7. The outline of South China Sea block as show in these figures has drastic variation compared with the surrounding areas, where the anomaly value is greater than or less that of the surrounding areas and there is a clearly visible boundary between the geological tectonic units. Based on the above characteristics, the microplate boundary in the South China Sea block is described. According to Figs. 6 and 7, South 
China Sea block is divided into four tectonic blocks, as shown in Fig. 9. Qiongtai tectonic block is located in the northernmost part of the South China Sea block, which is adjacent to South China block, including the Beibu Gulf Basin, the Pearl River Basin and other sedimentary basins. It is the transition between South China Sea block and South China block. Considering Figs. 6 and 7, we can see that the zhongxisha tectonic block and the central basin tectonic block are in the middle of South China Sea block, and the zhongxisha tectonic block is situated in the west of the central basin. This is particularly evident in Fig. 7, where the North-South boundary of the two tectonic blocks is clearly distinguished from the other two tectonic blocks. It can be seen from the figure that the central basin tectonic block are distributed from in a rhombus shape, which is formed by the expansion of the New South China Sea with the oceanic crust as the basement. The Nansha tectonic block is located at the southernmost end of South China Sea block.

\subsubsection{Yunnan-Myanmar Active Tectonic Block Region}

Yunnan-Myanmar active tectonic block is located in South China, to the south of the east tectonic line of Qinghai-Tibet Plateau. Figure 9 shows this tectonic block region consists of Western Yunnan and Southern Yunnan tectonic blocks. This tectonic block is dominated by strike-slip earthquake, with complex fault types. Yunnan-Myanmar active tectonic block region is closely adjacent to South China active tectonic block region. Its east boundary is the west margin of South China active tectonic block region and west boundary is the Myanmar arcuate plate subduction zone; in its middle is the Nujiang-Lancangjiang fault zone, which divides this region into Western Yunnan and Southern Yunnan tectonic blocks. Due to scarcity of geophysical data of this region, Figs. 2, 3, 6, and 7 cannot clearly delimit the boundaries of the microplates, therefore Fig. 9 does not completely indicate the detail outline of this region, which entails further study in the future.

\subsubsection{Qinghai-Tibet Active Tectonic Block Region}

Qinghai-Tibet Plateau is a unique geological unit which has complex topography and very active geological tectonic movement. As seen in Fig. 9, the Qinghai-Tibet Plateau tectonic block has the Altyn Tagh-Haiyuan fault zone as its north boundary, Longmenshan Mountains-Xiaojiang fault zone as its east boundary, Himalaya collision zone as its south boundary and Karakoram fault zone as its west boundary, which is largely identical to the zoning proposed by Tang (2003). Slightly unlike the work of Zhang et al. (2003), this paper identifies West Qinling fault zone, Kunlun fault zone, Xianshuihe fault zone, and Jiali fault zone as the boundaries of Qi-lian, Qaidam, Bayan Har, Qiangtang, and Lhasa tectonic blocks respectively; the upward exten- sion of Nujiang-Lancangjiang fault zone is the boundary between Yunnan-Myanmar and Qiangtang tectonic blocks. Figure 9 clearly identifies the boundary of geological units of Qinghai-Tibet active tectonic block region. This region is roughly shaped like a spindle, in which the interior has mild variation while the periphery has drastic variation in amplitude. This active tectonic block region has extensive presence of large number of active faults; the low-altitude areas around the plateau mostly have thrust faults (Molnar and Tapponnier 1975; Taylor and Yin 2009); the interior high-altitude areas are dominated by SN normal faults and conjugated strike-slip faults, which is closely associated with the outward squeezing effect of this tectonic block and the nearly EW extension effect of its interior (Armijo et al. 1986). The Longmenshan fault zone, Altyn Tagh-Haiyuan fault zone and Himalaya thrust-napped zone are all thrust faults; the East Kunlun fault zone, Xianshuihe fault zone, and Jiali fault zone are strike-slip faults.

\subsubsection{Western Active Tectonic Block Region}

The Western Regions tectonic block region is located to the north of Qinghai-Tibet active tectonic block region. Figure 9, roughly referencing the zoning principle proposed by Zhang et al. (2003) and the zones identified in Figs. 2, 3, 6, and 7, divides this tectonic block into 6 tectonic blocks, i.e., Tarim, Tianshan, Junggar, Alxa, Altai, and Sayan. Similar to Northeast Asia active tectonic block region, the outline of this active tectonic block region has been updated according to the identification results in this paper.

Tarim Basin is a stable region in the center of the Tarim plate and is surrounded by the orogenic belts such as Southern Tianshan, West Kunlun, and Altyn Tagh. As seen in Figs. 7c, d, and e, this basin contains a large EW fault zone. Tianshan Mountains is located in the north of Tarim tectonic block and south of Junggar tectonic block, it has complex interior structure, deformation mostly occurs in front of and inside mountains and is dominated by foreland basin folds and thrust faults and its periphery is dominated by thrust fault zones (Burchfiel et al. 1999). The gradient and fault zone of Junggar tectonic block, located to the north of the Tianshan block, is generally similar to Tarim tectonic block. Its interior has mild variation and the periphery has drastic increase in amplitude.

\section{CONCLUSION}

Compared with other investigations' results, high precision, high resolution satellite gravity data can reflect more detailed geophysical information and more efficiently. Meanwhile, compared with other expensive and difficult to popularize technologies, the boundary identification methods can provide certain geophysical supports for geological structure analysis and crustal dynamic process in the study 
area. By using the high precision and high resolution satellite gravity data, the paper updates the boundaries of tectonic plates in East Asia, infers the tectonic unit boundary between the North China and South China active tectonic block regions, redefines the extension route of Red River fault, and the East Asia is divided into tectonic zones. We use satellite gravity full-tensor gradient data and its combinations to identify the tectonic boundaries of underground faults, contact zones and other tectonic units and thereby divide the geological tectonic units of East Asia, identify the general outlines of the microplates and provide the tectonic basis for geological interpretation. Based on the above methods, we draw the following conclusion:

(1) Free-air gravity anomalies alternate with each other, which correspond to the positive and negative structures geologically and the geotectonic structure of China. The east and west parts of China mainland have significant difference in Bouguer gravity anomaly. Bouguer gravity anomaly is well indicative of the basic geotectonic characteristics of China mainland. Due to the strong effects of the surrounding plates, China and surrounding regions have unique lithospheric stress field and clearly distinguishable zones.

(2) By comprehensively referencing the previous studies on China mainland by other people and by using the boundary identification methods based on the satellite gravity fulltensor gradient data and its combinations, we investigate the tectonic boundary characteristics of China and surrounding regions. Section 4.3 updates the extension route of Red River fault zone and deduces that Xinyang-Jinzhai fault zone and the east part of Changhua-Putuo fault zone may constitute the tectonic unit boundary between the North China and South China active tectonic block regions. Section 4.4 updates the boundaries of tectonic plates in East Asia and identifies in China and surrounding regions 6 primary active tectonic blocks, 22 secondary active tectonic blocks, 7 tertiary active tectonic blocks, and the 20 active tectonic block boundary zones constituted of deformation belts and active tectonic belts with various geometric structures and width variations. The main contact zones are the boundaries of the vast majority of the active tectonic blocks, while the secondary faults are mostly present within the aforesaid tectonic zones.

Acknowledgements We thank the D. Sandwell of UCSD for providing the gravity model and topography model (ftp://topex.ucsd.edu/pub/archive/). We also express our sincere gratitude to the editors and reviewers in improving the manuscript. All figures were created using Generic Mapping Tools software (Wessel and Smith 1998).

\section{REFERENCES}

Armijo, R., P. Tapponnier, J. L. Mercier, and T.-L. Han,
1986: Quaternary extension in southern Tibet: Field observations and tectonic implications. J. Geophys. Res.,91, 13803-13872, doi: 10.1029/jb091ib14p13803. [Link]

Avouac, J.-P. and P. Tapponnier, 1993: Kinematic model of active deformation in central Asia. Geophys. Res. Lett., 20, 895-898, doi: 10.1029/93g100128. [Link]

Bell, R. E., R. Anderson, and L. Pratson, 1997: Gravity gradiometry resurfaces. The Leading Edge, 16, 55-59, doi: 10.1190/1.1437431. [Link]

Burchfiel, B. C., E. T. Brown, D. Qidong, F. Xianyue, L. Jun, P. Molnar, S. Jianbang, W. Zhangming, and Y. Huichuan, 1999: Crustal Shortening on the Margins of the Tien Shan, Xinjiang, China. Int. Geol. Rev., 41, 665-700, doi: 10.1080/00206819909465164. [Link]

Cordell, L., 1979: Gravimetric expression of graben faulting in Santa Fe Country and the Espanola Basin, New Mexico. In: Ingersoll, R. V., L. A. Woodward, H. L. James, (Eds.), New Mexico Geological Society 30th Annual Fall Field Conference Guidebook, New Mexico Geological Society, Santa Fe Country, 59-64.

Cordell, L. and V. J. S. Grauch, 1985: Mapping basement magnetization zones from aeromagnetic data in the San Juan Basin, New Mexico. In: Hinze, W. J. (Ed.), The Utility of Regional Gravity and Magnetic Anomaly Maps, Society of Exploration Geophysicists, 181-197, doi: 10.1190/1.0931830346.ch16. [Link]

Dai, W., D. Huang, T. Li, and G. Zhang, 2018: The edge detection method and its application in the south China sea based on the gravity gradient structure tensor eigenvalue. Chinese J. Geophys., 61, 2494-2507, doi: 10.6038/cjg2018M0018. (in Chinese with English abstract) [Link]

Deng, Q., P. Zhang, Y. Ran, X. Yang, W. Min, and L. Chen, 2003a: Active tectonics and earthquake activities in China. Earth Science Frontiers, 10, 66-73. (in Chinese with English abstract)

Deng, Q., P. Zhang, Y. Ran, X. Yang, W. Min, and Q. Chu, 2003b: Basic characteristics of active tectonics of China. Sci. China Ser. D-Earth Sci., 46, 356-372, doi: 10.1360/03yd9032. [Link]

Fedi, M., L. Ferranti, G. Florio, I. Giori, and F. Italiano, 2005: Understanding the structural setting in the southern Apennines (Italy): Insight from gravity gradient tensor. Tectonophysics, 397, 21-36, doi: 10.1016/j. tecto.2004.10.012. [Link]

Fullea, J., M. Fernàndez, and H. Zeyen, 2008: FA2BOUGA FORTRAN 90 code to compute Bouguer gravity anomalies from gridded free-air anomalies: Application to the Atlantic-Mediterranean transition zone. Comput. Geosci., 34, 1665-1681, doi: 10.1016/j.cageo.2008.02.018. [Link]

Gao, L.-K., F.-Y. Jiang, and L.-Y. Huang, 2011: Research on Faults and Structures of Hulin Basin in 
Heilongjiang Province by Gravity Gradient Tensor. Geological Journal of China Universities, 17, 281286. (in Chinese with English abstract)

Guo, F., Z. Sun, Z. Zhai, and Y. Xiao, 2017: Tectonic stress field in Bohai Bay area inversed by multi-source gravity observation data. Geomatics and Information Science of Wuhan University, 42, 136-142, doi: 10.13203/j.whugis20140743. (in Chinese with English abstract) [Link]

Han, Z., J. Xu, Y. Ran, L. Chen, and X. Yang, 2003: Active blocks and strong seismic activity in North China region. Sci. China Ser. D-Earth Sci., 46, 153-167, doi: 10.1360/03dz0012. [Link]

Li, S. G., 1973: Introduction to Geomechanices, Science Press, Beijing. (in Chinese)

Ma, Z.-J., X.-L. Gao, and Z.-F. Song, 2006: Analysis and tectonic interpretation to the horizontal-gradient map calculated from Bouguer gravity data in the China mainland. Chinese J. Geophys., 49, 95-106, doi: 10.1002/cjg2.816. (in Chinese with English abstract) [Link]

Mickus, K. L. and J. H. Hinojosa, 2001: The complete gravity gradient tensor derived from the vertical component of gravity: A Fourier transform technique. $J$. Appl. Geophys., 46, 159-174, doi: 10.1016/s09269851(01)00031-3. [Link]

Mikhailov, V., G. Pajot, M. Diament, and A. Price, 2007: Tensor deconvolution: A method to locate equivalent sources from full tensor gravity data. Geophysics, $\mathbf{7 2}$, I61-I69, doi: 10.1190/1.2749317. [Link]

Miller, H. G. and V. Singh, 1994: Potential field tilt-A new concept for location of potential field sources. J. Appl. Geophys., 32, 213-217, doi: 10.1016/09269851(94)90022-1. [Link]

Molnar, P., 1990: A review of the seismicity and the rate of the active underthrusting and deformation at the Himalaya. Journal of Himalayan Geology, 1, 131-154.

Molnar, P. and P. Tapponnier, 1975: Cenozoic Tectonics of Asia: Effects of a Continental Collision: Features of recent continental tectonics in Asia can be interpreted as results of the India-Eurasia collision. Science, 189, 419-426, doi: 10.1126/science.189.4201.419. [Link]

Nabighian, M. N., 1984: Toward a three-dimensional automatic interpretation of potential field data via generalized Hilbert transforms: Fundamental relations. Geophysics, 49, 780-786, doi: 10.1190/1.1441706. [Link]

Roest, W. R., J. Verhoef, and M. Pilkington, 1992: Magnetic interpretation using the 3-D analytic signal. Geophysics, 57, 116-125, doi: 10.1190/1.1443174. [Link]

Tang, F. T., 2003: A study on the characteristics of recent tectonic deformation and earthquake activity in North China. Graduate Institute of Geology, China Earthquake Administration, Beijing. (in Chinese with English abstract)
Tapponnier, P., G. Peltzer, A. Y. Le Dain, R. Armijo, and P. Cobbold, 1982: Propagating extrusion tectonics in Asia: New insights from simple experiments with plasticine. Geology, 10, 611-616, doi: 10.1130/0091-7613(1982)10<611:petian>2.0.co;2. [Link]

Taylor, M. and A. Yin, 2009: Active structures of the Himalayan-Tibetan orogen and their relationships to earthquake distribution, contemporary strain field, and Cenozoic volcanism. Geosphere, 5, 199-214, doi: 10.1130/ges00217.1. [Link]

Teng, C.-T., Y.-M. Chang, K.-L. Hsu, and F.-T. Fan, 1979: On the tectonic stress field in China and its relation to plate movement. Phys. Earth Planet. Inter., 18, $257-$ 273, doi: 10.1016/0031-9201(79)90063-3. [Link]

Tenzer, R., M. Eshagh, and W. Shen, 2017: The sub-crustal stress estimation in central Eurasia from gravity, terrain and crustal structure models. Geosci.J., 21, 47-54, doi: 10.1007/s12303-016-0036-7. [Link]

Verduzco, B., J. D. Fairhead, C. M. Green, and C. MacKenzie, 2004: New insights into magnetic derivatives for structural mapping. The Leading Edge, 23, 116-119, doi: 10.1190/1.1651454. [Link]

Wang, Q., P.-Z. Zhang, J. T. Freymueller, R. Bilham, K. M. Larson, X. Lai, X. You, Z. Niu, J. Wu, Y. Li, J. Liu, Z. Yang, and Q. Chen, 2001: Present-Day Crustal Deformation in China Constrained by Global Positioning System Measurements. Science, 294, 574-577, doi: 10.1126/science.1063647. [Link]

Wessel, P. and W. H. F. Smith, 1998: New, improved version of generic mapping tools released. Eos Trans. $A G U, 79,579-579$, doi: 10.1029/98eo00426. [Link]

Wijns, C., C. Perez, and P. Kowalczyk, 2005: Theta map: Edge detection in magnetic data. Geophysics, 70, L39L43, doi: 10.1190/1.1988184. [Link]

Xie, F.-R., X.-F. Cui, J.-T. Zhao, Q.-C. Chen, and H. Li, 2004: Regionalization of the recent tectonic stress field in China and adjacent regions. Chinese J. Geophys., 47, 745-754, doi: 10.1002/cjg2.3545. (in Chinese with English abstract) [Link]

Xiong, S., H. Yang, Y. Ding, and Z. Li, 2018: Subdivision of tectonic units in China based on aeromagnetic data. Geology in China, 45, 658-680, doi: 10.12029/ gc20180402. (in Chinese with English abstract) [Link]

Xu, J., Z. Zao, Y. Ishikawa, and K. Oike, 1988: Properties of the Stress Field in and around West China Derived from Earthquake Mechanism Solutions. Bulletin of the Disaster Prevention Research Institute, Kyoto University, 38, 49-78.

Xu, J.-R., Z.-X. Zhao, and Y. Ishikawa, 2008: Regional characteristics of crustal stress field and tectonic motions in and around Chinese mainland. Chinese J. Geophys., 51, 770-781. (in Chinese with English abstract)

Yang, W. C., Z. X. Chen, Z. Z. Hou, and X. H. Meng, 2016: 
Crustal density structures around Chinese continent by inversion of satellite gravity data. Acta Geologica Sinica, 90, 2167-2175. (in Chinese with English abstract) You, Y.-X., 1994: A Research on the Conversion of Gravity Field into Regional Tectonic Stress Field. Acta Geophysica Sinica, 37, 259-272. (in Chinese with English abstract)

Yu, P., Q. Zhang, and C. Zhang, 2019: A new method of balanced edge detection for the gravity potential-field based on horizontal analytical signal. Chinese J. Geophys., 62, 3734-3743, doi: 10.6038/cjg2019M0500. (in Chinese with English abstract) [Link]

Zhang, G.-M., H.-S. Ma, H. Wang, and X.-L. Wang, 2005: Boundaries between active-tectonic blocks and strong earthquakes in China mainland. Chinese J. Geophys., 48, 662-671, doi: 10.1002/cjg2.699. (in Chinese with English abstract) [Link]

Zhang, P., Q. Deng, G. Zhang, J. Ma, W. Gan, W. Min, F. Mao, and Q. Wang, 2003: Active tectonic blocks and strong earthquakes in the continent of China. Sci. China Ser. D-Earth Sci., 46, 13-24, doi: 10.1360/03dz0002. [Link]

Zhang, P. Z., Q. D. Deng, Z. Q. Zhang, and H. B. Li, 2013: Active faults, earthquake hazards and associated geodynamic processes in continental China. Science China Earth Science, 43, 1607-1620. (in Chinese)

Zhao, B., Y. Huang, C. Zhang, W. Wang, K. Tan, and R. Du, 2015: Crustal deformation on the Chinese mainland during 1998-2014 based on GPS data. Geod. Geodyn., 6, 7-15, doi: 10.1016/j.geog.2014.12.006. [Link]

Zhao, S., Z. Jin, and W. Gan, 2012: A preliminary study of the focal mechanism of the deep-focus earthquakes in Northeast China. Earth Science Frontiers, 19, 300311. (in Chinese with English abstract)

Zhdanov, M. S., R. Ellis, and S. Mukherjee, 2004: Threedimensional regularized focusing inversion of gravity gradient tensor component data. Geophysics, 69, 925937, doi: 10.1190/1.1778236. [Link] 